\title{
El problema del amateurismo y el profesionalismo deportivo en la URSS: 1941-1991*
}

\section{The problem of amateur sportsmanship and professionalism in the USSR: 1941-1991}

DAVID SEBASTIÁN IBARROLA

Instituto de Investigaciones Gino Germani. Universidad de Buenos Aires. Argentina

C/Pres. José Evaristo Uriburu, 950. C1114 AAD- Buenos Aires

david.ibarrola92@gmail.com

ORCID: https://orcid.org/0000-0001-5154-4938

Recibido: 24-06-2020. Aceptado: 21-12-2020.

Cómo citar / Citation: Ibarrola, D. S. (2020). El problema del amateurismo y el profesionalismo deportivo en la URSS: 1941-1991. Ágora para la Educación Física y el Deporte, 22, 146-166.

DOI: https://doi.org/10.24197/aefd.0.2020.146-166

Resumen: El propósito de este trabajo es continuar con la indagación acerca del deporte soviético. Apoyándome en la bibliografía historiográfica pertinente, abordaré el problema del amateurismo y el profesionalismo en el período que abarca la segunda guerra mundial hasta la caída de la URSS, en referencia al modelo deportivo de dicho Estado. De este modo, me propongo completar lo comenzado en un trabajo previo, que abarcaba los primeros años del deporte soviético, para así aportar una perspectiva que permita observar el desenvolvimiento de aquellos aspectos del deporte que se desarrollaban de forma potencial en aquellos tiempos.

Palabras clave. Deporte; política; profesionalismo; estado; socialismo.

Abstract: The purpose of this paper is to continue the inquiry about Soviet sport. Leaning on the relevant historiographical bibliography, I will address the problem of amateurism and professionalism in the period that covered the Second World War until the fall of the USSR, referring to the sports model of that State. In this way, I intend to complete what I started in a previous work, which covered the first years of Soviet sport, in order to provide a perspective that allows us to observe the development of those aspects of sport that were potentially developed in those times.

Keywords: Sport; politics; professionalism; state; socialism.

\footnotetext{
* Este trabajo fue realizado en el marco de mi Beca Interna Doctoral CONICET, bajo la dirección
} de la Dra. Verónica Moreira. 


\section{INTRODUCCIÓN}

El presente trabajo pretende continuar con algunos puntos abordados en el texto "Reflexiones acerca del deporte soviético: de la revolución a la adaptación a occidente" (Ibarrola, 2018), en el cual se intenta comprender las discusiones y virajes que se producían en los primeros años (1917-1941) de la URSS respecto al deporte. Allí se dio cuenta del pasaje de una concepción de deporte integral, higienista, vinculada al trabajo y la actividad militar, denominada "deporte obrero" (García del Valle, 2016), hacia una pensada para la competencia y la rivalidad en récords con los países capitalistas, el "deporte burgués". En esta ocasión, me interesa profundizar en el desenvolvimiento de la discusión acerca del amateurismo- profesionalismo en la URSS, en relación al modelo deportivo en dicho Estado durante el periodo que abarca desde el final del pacto Hitler-Stalin ${ }^{1}$ (1941) hasta la caída de la URSS (1991). Para lograr esto apelaré a la bibliografía pertinente, especialmente el libro "Serious fun: a history of spectator sports in the USSR (1993)" de Robert Edelmann, y los distintos aportes del historiador James Riordan. Para iniciar, repasaremos brevemente lo ya trabajado para las primeras décadas deportivas de la URSS.

\section{EL DEPORTE EN LA URSS: PRIMEROS AÑOS}

La concepción dominante en los primeros años de la URSS era la del "deporte obrero". Este era entendido como algo propio del movimiento socialista y los trabajadores, vinculado a las aspiraciones de la sociedad soviética. Se trataba del "modelo absoluto para los deportistas con conciencia de clase" (Gounot, 2007, p.10), el cual "no participará en las competiciones del deporte burgués" (Gounot, 2007, p.10). Era un deporte abierto, sin distinción de género ni nacionalidad, una alternativa al chauvinismo, comercialismo y contrario a aspirar a los récords. Internacionalista y anti-elitista, se consideraba verdaderamente amateur. Su objetivo no era la exaltación del atleta, sino la auto-superación, el bienestar y la puesta a punto para la lucha de clases, contribuyendo a

\footnotetext{
${ }^{1}$ También conocido como pacto Ribbentrop-Mólotov, era un acuerdo de no agresión entre los nazis y la URSS, firmado en 1939. Este pacto se quebró cuando Alemania invadió la URSS en 1941.
} 
liberar a los trabajadores del control e influencias de la burguesía. Se trata de una concepción higienista, la cual no consistía "en ejercicios físicos per se, sino en un régimen higiénico que dura día y noche" y comprendía "las condiciones de la vida personal y social, el sueño, el descanso, la ropa, la alimentación y el trabajo" (Gounot, 2007, p.15). El deporte era concebido como un agente del cambio social, que educaría a las masas en los mejores hábitos de higiene, nutrición y ejercicio (Riordan, 2007), a través de la cultura física ${ }^{2}$. Esto es importante teniendo en cuenta que "El desarrollo comunista, se basó inicialmente en una masa de población rural y analfabeta" (Riodan, 2007, p.110). Así, mediante el deporte, se combatiría el crimen, la delincuencia juvenil, el alcoholismo y la prostitución, contribuyendo a la emancipación social de la mujer. Se trata de un enfoque que promovía el ideal de un "hombre nuevo", igualitario, trabajador y disciplinado.

No se pueden divorciar estas ideas sobre deporte, de los debates en la URSS. Uno de los grupos más activos y hegemónicos en los primeros años, era el prolekultista "que creía que todo el deporte de competición era 'un vestigio de la sociedad burguesa', y deseaba su desaparición en el marco de una completa transformación de la vida cotidiana dentro del sistema soviético" (Gounot, 2007, p.12). Este deporte produciría "numerosos perjuicios para la salud por una especialización extrema, alentando el comercialismo y el profesionalismo" (Truan, 2008, p.13) convirtiendo a las masas "en meros espectadores pasivos" (Truan, 2008, p.13). El eje estaba puesto en actividades como ciclismo, natación, acrobacias y gimnasia (Riordan, 2006), y no en otras como el fútbol y el boxeo, que se consideraban alejadas del ideal de beneficio para la salud, llegando incluso a ser prohibidas. La oposición a la idea de "ganar como sea" era fuerte en este grupo: "El deporte debería ser limpio, puro y estimulante, purgando al revolucionario de cualquier simpatía por el deporte capitalista" (Riordan, 2006, p.475). Por el contrario, promovían "Una innovación revolucionaria de la cultura física proletaria que tomaría la forma de gimnasia laboral, exhibiciones de masas, desfiles, concursos

\footnotetext{
${ }^{2}$ La cultura física o Fiskultura, era la denominación para el deporte y la actividad física educativa y recreativa, que no estaba influida por el capitalismo y con el que pretendía fomentar la práctica de actividades físicas entre los trabajadores (Truan, 2008, p.13).

${ }^{3}$ Se utilizará la cursiva para términos que no provengan de la lengua española.

${ }^{4}$ Prolekult: Federación de artistas e intelectuales de vanguardia, que concebía al deporte en tanto parte integral de la "cultura proletaria".
} 
y excursiones" (Riordan, 2006, p.469). Se trata de una concepción integral y participativa que no se limitaba a los fenómenos considerados propiamente deportivos 5 . Además, afirmaban que "Las competiciones deportivas introducían en los ciudadanos actitudes extranjeras, individualistas y burguesas, que eran peligrosas para una sociedad socialista" (Truan, 2008, p.94).

En consonancia con el internacionalismo comunista, el "deporte obrero" tenía su propia organización mundial, la Internacional Roja del Deporte y la Gimnasia, y su propia contra-olimpíada, la "espartaquiada", una demostración física y deportiva, preparatoria para la lucha por el socialismo. Ella incluía también contenidos no estrictamente deportivos, como eventos militares, bailes folklóricos y otras actividades no competitivas (Edelman 1993).

Desde luego, en la URSS el control del deporte estaba financiando y fuertemente centralizado en el Estado, concentrado en la persona del dirigente máximo del comité a cargo del deporte, quien supervisaba toda la actividad. Existían asociaciones locales, vinculadas al ejército (CSKA), el sindicalismo (Torpedo, Dinamo o Lokomotiv), y en otros casos a las universidades o colectividades agrarias.

Este conjunto de ideas fue perdiendo terreno hacia fines de la década de 1920. El primer paso fue la aceptación del deporte de competencia (especialmente el fútbol) en el interior de la URSS. Luego se abandonó la creencia de algunas particularidades del deporte soviético, en favor del estudio de las mejores técnicas y avances del deporte occidental, otrora contenidos propios del "deporte burgués" . El énfasis en la competencia ${ }^{7}$ iría acompañado del estímulo stajanovista ${ }^{8}$ al rendimiento ${ }^{9}$, dejando de

\footnotetext{
${ }^{5}$ Entendido esto como actividades físicas e intelectuales, humanas, competitivas y regidas por reglas institucionalizadas (García Ferrando, 1990)

${ }^{6}$ De acuerdo con los representantes del "deporte obrero", el "deporte burgués" se caracterizaba por el "fomento de la competitividad, el rendimiento y el individualismo, era un reflejo de los principales valores de la sociedad capitalista y que los transmitía a un tiempo a los practicantes deportivos y a los espectadores" (Gounot, 2007, p.10) En el, los países compiten entre sí fomentando el nacionalismo y la rivalidad entre los pueblos. Se trata de una actividad mercantilizada, que se jacta de su neutralidad y su apoliticismo.

${ }^{7}$ Asimismo, el aislamiento deportivo soviético comenzó a romperse de forma gradual. En la medida en que el Estado buscó alianzas con los gobiernos burgueses contra el fascismo, los deportistas soviéticos pudieron medirse con sus pares de países como Francia, Bélgica y Turquía. Anteriormente, solo se realizaban encuentros con asociaciones vinculadas al comunismo internacional

${ }^{8}$ Movimiento que promovía el aumento de la productividad laboral
} 
lado la actividad deportiva colectivista. La preocupación económica por los récords productivos (con repercusión salarial) se trasladaría al deporte, y emergerían las recompensas a los "campeones", con primas y privilegios, generándose sistemas de clasificación y medallas que construían jerarquías entre los deportistas, ahora motivados para elevar su rendimiento. Ellos se transformarían en modelos y estrellas idolatradas por las multitudes. Estos cambios signaron el período previo a la segunda guerra mundial: gradualmente, la mirada de las organizaciones soviéticas se había concentrado en un grupo reducido de deportistas de primera fila, con marcas muy destacadas a nivel internacional. En 1934 la consigna fue superar los récords burgueses en el deporte, alentado con una buena dosis de patriotismo. Ya no se ponían reparos para competir contra equipos burgueses. Asimismo, las autoridades mutaron de una crítica hacia el amateurismo elitista de los Juegos Olímpicos, a tomar reservas y criticar públicamente actividades profesionalizantes que existían en la URSS.

Es que, de algún modo $\mathrm{u}$ otro, ya sea mediante disimulados estipendios o "regalos", sueldos en calidad de instructores deportivos, o puestos de trabajo a los que no concurrían, desde siempre (del mismo modo que en el resto del mundo) los grandes deportistas recibían una recompensa por su actividad. Este cuadro se profundizó durante la NEP $(1921-1929)^{10}$, cuando surgieron operadores deportivos, quienes buscaban lucrar con los pases de los deportistas. Si bien esto era visto como un acto de bienestar individual frente al colectivo (un síntoma de profesionalismo) en la práctica era imprescindible para la subsistencia de los clubes: se trató de un semi-profesionalismo, en un contexto semicapitalista. "Las pequeñas competencias rápidamente volvieron común la entrega como premio de sumas de dinero, se volvieron frecuentes partidos amistosos, giras por el interior con fines lucrativos que "escapaban" los controles oficiales y repartían la recompensa entre los deportistas" (Ibarrola, 2018, p.13).

\footnotetext{
${ }^{9}$ Como parte del programa "Preparación para el Trabajo y Defensa de la URSS", en 1935 se estableció una clasificación (revisada cada cuatro años, como un periodo olímpico), para reflejar los nuevos estándares de perfección alcanzados en el deporte. El programa reconocía la competencia en 15 tipos de eventos, vinculados a lo militar, higiene y deporte (Parks, 2009). ${ }^{10}$ Nueva Política Económica, que implico un incentivo a la iniciativa privada, pero limitada y
controlada.
} 
Las crecientes preocupaciones por la competitividad reforzaron esto una vez terminada la NEP. Los deseos de aumentar la misma llevaron a una modificación por ejemplo, de la liga de fútbol, dando lugar a un modelo que imitaba las virtudes de las ligas capitalistas (Edelman, 1993), las cuales fomentaban la competencia entre los futbolistas por el puesto en el equipo. La frecuencia del entrenamiento aumentó notoriamente y se obtenían permisos laborales para las pretemporadas. El deporte se sistematizaba, tendía a volverse una actividad de tiempo completo.

Sin embargo, a diferencia de en otros países, no se llegó a una profesionalización. La tendencia mundial a volverse profesional, tuvo un impacto particular en la URSS: el profesionalismo fue de facto, pero no formal. $\mathrm{Su}$ reconocimiento y formalización, como veremos, tardaría varias décadas. Este amateurismo, cuya falsedad era de conocimiento de los espectadores, se combinó con una serie de convenientes y ocasionales denuncias en la prensa de profesionalismo y montaje de empresas deportivas. Esto debido a que se defendía de palabra un deporte anticomercial, anti-elitista, en donde el deportista no era una mercancía.

La disolución de unos de los principales organismos del "deporte obrero", la Internacional Roja del Deporte y la Gimnasia, no fue una sorpresa, ya que también se produjo un cambio de posición frente a las olimpiadas. Otrora consideradas elitistas y nacionalistas, promotoras de métodos tayloristas (Rodríguez Quijada y Molkova,2018), ahora los soviéticos comenzaban a realizar esfuerzos por integrarse a ese movimiento olímpico internacional (y a las asociaciones internacionales de los distintos deportes): el llamado al boicot a Berlin 1936 lejos está de ser un rechazo al mismo, sino más bien expresa que "se acepta los ideales de los olímpicos como genuinos, el pacifismo, la igualdad racial denunciando a los nazis por su violación" (Ibarrola, 2018, p.12). Sin embargo, para la integración defintiva al circuito deportivo internacional, restaba resolver la cuestión del amateurismo, formato bajo el cual se competía en la mayoría de los deportes y en las olimpiadas. Este eje será discutido en las siguientes páginas, desde la caída del pacto entre la URSS y Alemania (1941) hasta la disolución de la propia URSS.

\section{DE LA GUERRA A LA PERESTROIKA}

El ingreso de la URSS a la guerra, lejos estuvo de detener la actividad deportiva. En muchas de las ciudades ocupadas o en disputa, como Leningrado y Kiev, se organizaban partidos que servían para 
mantener la moral alta y alterar la rutina. Por ejemplo, en 1943 se organizó en Moscú un campeonato de fútbol y en 1944 volvió el básquet. Ese mismo año se retomaron los vínculos internacionales, con un amistoso en Irán del Dinamo Tblisi. Pero al mismo tiempo se reinició la compra y venta de jugadores: "las leyes de hierro del deporte profesional aplicaban al escenario soviético, cuando los jugadores se quedaban en un lugar mientras fueran útiles" (Edelman, 1993, p.83). A pesar de la destrucción de la infraestructura ${ }^{11}$ producto de la guerra, el deporte volvió rápidamente a su ritmo habitual, e incluso amplió su base social y nacional, llenando estadios. Al igual que en el resto del mundo, los años de posguerra fueron grandiosos para el deporte de espectador ${ }^{12}$.

Los rasgos señalados en el apartado previo, se profundizaron. Por ejemplo, en 1945 el Dinamo Moscú tuvo una exitosa gira por Gran Bretaña, cuyo resultado fue atribuido a la otrora "burguesa" formación en W. Como contrapartida, el trabajo político e ideológico de los deportes parecía ser determinante a la hora de explicar un triunfo, una derrota o un mal comportamiento. Asimismo, se asistió a un patriótico intento de rusificar los términos de los deportes más populares, mayormente de origen inglés ${ }^{13}$ (Riordan, 1994). Uno de los rasgos característicos de este período, las purgas, no fue ajeno al mundo deportivo. Nikolai Starostin, ídolo deportivo del fútbol y el hockey, fue acusado de promover el "deporte burgués" en la sociedad soviética y condenado al gulag ${ }^{14}$ (Riordan, 1994).

Por otro lado, los desfiles deportivos populares perdieron importancia, así como el deporte de masas lo hizo frente al de alto rendimiento que competiría internacionalmente. Ahora el objetivo era el prestigio y la gloria en los Juegos Olímpicos para demostrar la vitalidad y superioridad del socialismo (Riordan, 1988b). La posguerra encontró a la URSS luchando y logrando ingresar en los organismos internacionales ${ }^{15}$.

\footnotetext{
${ }^{11}$ La ausencia de lugares para entrenar llevo a que muchos equipos de futbol deban practicar otras actividades para mantenerse en forma

${ }^{12}$ Esto en parte debido a la recuperación industrial, y sobre todo algunas medidas tomadas tras la muerte de Stalin, tales como la reducción de la jornada laboral a seis horas (Broue, 1973)

${ }^{13}$ Por ejemplo el fútbol se transformó en nozhnoi myac, el referi, en sudya, y el corner, en uglovoi.

${ }^{14}$ Campos de trabajos forzados.

15 En 1946 la URSS integrará la FIFA y la IAAF International Association of Athletics Federations
} 
El deporte soviético produjo una elite deportiva que fue utilizada como una herramienta para promocionar las bondades del régimen (Sparks, 2009) en las grandes competencias mundiales, incluidas las olimpiadas de Helsinski 1952. Las presiones por la victoria llevaron a la caída en desgracia de varios deportistas que no cumplían las expectativas, perdiendo las medallas y títulos deportivos honoríficos soviéticos. Si la URSS no participó de las olimpiadas de 1948, esto se debió principalmente a las dudas de una victoria segura de los representantes soviéticos: había que demostrar la superioridad del socialismo. En cambio, envió una comitiva en calidad de observadores. En 1951 se integraría al Comité Olímpico Internacional (COI). Como "prenda" de ingreso a este mundo ${ }^{16}$, el principal cambio estuvo en que la URSS se vio obligada a reconocer el amateurismo ${ }^{17}$ de sus deportistas mediante una resolución gubernamental de 1947, la cual prohibía las recompensas financieras para los competidores, y establecía como único premio por su actividad las medallas que obtuviesen (Riordan, 1988a). Así, se reforzó la largamente sostenida ficción ${ }^{18}$.

Con la "coexistencia pacífica"19 y la "desestalinizacón "20, bajo Kruschev (1953-1964) no se produjeron grandes cambios. Más bien se prolongó esta situación, a pesar de algunas reformas administrativas ${ }^{21}$.

\footnotetext{
${ }^{16}$ Sparks (2009) observa como positiva la presencia soviética en la evolución de los Juegos Olímpicos, fomentando la incorporación de nuevos miembros y la competencia de las mujeres.

${ }^{17}$ De acuerdo con Sparks, para el COI esto significaba una persona cuya conexión con el deporte "es y siempre ha sido únicamente por placer y por beneficios físicos, mentales y sociales de los que deriva y para quienes el deporte no es nada más que recreación sin ganancia material de ningún tipo, directa o indirecta" (Sparks, 2009, p.32). El mismo autor señala que la concepción de los soviéticos sobre el fenómeno era similar a la de las socialdemocracias europeas "En 1946, representantes suecos del atletismo amateur sueco, propusieron cambiar las reglas de amateurismo de la actividad para permitir compensación a los atletas por el tiempo fuera del trabajo para participar competiciones" (Sparks, 2009, p.92)
}

${ }^{18}$ Esto debido a que los deportistas seguían concentrando en campos deportivos, eran liberados de
sus trabajos, bien pagos por el gobierno y recibían alimentación especial.
${ }^{19}$ Referencia al tipo de relaciones que debían llevar Estados Unidos y la URSS.
${ }^{20}$ Se trata de la crítica al "culto a la personalidad" bajo el Stalinismo y la revelación de una serie
de crímenes ocurridos bajo su liderazgo. Para una crítica de los límites e intereses bajo la
"desestalinización", ver Broue (1973)
${ }^{21}$ Tras la muerte de Stalin en 1953, se realizaron reformas en el sistema deportivo soviético.
Disminuyó el control del gobierno, pasando nuevamente a los sindicatos y la juventud comunista.
Esto genero cambios ni mejores las condiciones del deporte local, por lo que en 1968 el gobierno
retomo el control, y puso al comité deportivo bajo la autoridad del consejo de ministros. Ninguno 
Las "espartaquiadas" fueron revividas en 1956, pero funcionando no como una contra-olimpiada, sino como la base de la estructura piramidal del sistema deportivo, es decir competencias locales, regionales y republicanas realizadas de forma periódica (un año antes de los Juegos Olímpicos) para detectar y seleccionar los representantes para las competencias internacionales. Eran unas "olimpiadas internas", en donde las disciplinas gimnasticas se llevaban toda la atención de los espectadores, ya que el básquet y el fútbol tenían sus propias ligas populares (Edelman, 1993).

Los resultados en las competencias internacionales fueron buenos en las olimpiadas, quizás aprovechando el estado semi-profesional (formalmente amateur) de sus deportistas, quienes enfrentaban a otros amateurs, pero malos en el fútbol no olímpico. Sobre este último, debido a la obsesión de los gobernantes por las medallas, se hizo muy difícil que los mejores atletas se dedicasen al fútbol. Además en este deporte, los soviéticos enfrentaron rápidamente a equipos profesionales debido a la llegada temprana del profesionalismo a la actividad. Los mismos resultados se daban en otros deportes, en la medida en que esto se extendía de forma gradual. Por ejemplo, en básquet algunos profesionales poco exitosos en Estados Unidos pasaron a las ligas amateurs europeas, rivalizando con los clubes soviéticos en las copas.

Ya durante el gobierno de Leonid Brezhnev (1964-1982), se dio un periodo caracterizado por Edelman (1993) como "conformista" en todos los ámbitos de la cultura, complejizándose la sociedad. Los ciudadanos, en promedio, dispusieron de más tiempo de ocio, aumentando la frecuencia de la visita a los estadios y la propia práctica deportiva. Junto con la ampliación y mejoras del transporte y las comunicaciones "Estadios, bases de entrenamiento, y escuelas deportivas fueron construidas en cantidades récord" (Edelman, 1993, p.157). Esto último, sumado a los precios accesibles, permite que los investigadores hablen de un boom en el entretenimiento, un gran desarrollo de la industria deportiva con récords de asistencia en los estadios durante los cincuenta y los sesenta. Allí el público seleccionó a sus favoritos: el fútbol, el hockey y el básquet, los cuales encabezaron la demanda. Asimismo, la creciente trasmisión por televisión de los encuentros deportivos inspiró a muchos ciudadanos a convertirse en atletas.

de estos cambios afectó al deporte de alto rendimiento, que ya había desarrollado su propio impulso 
Por el lado de los jugadores, en el fútbol se observa una menor de cantidad de horas de entrenamiento que los mejores equipos de Europa. También se desarrollan malos comportamientos, como peleas con árbitros y rivales, que en muchos casos también se trasladan a sus vidas personales: no asistencia a las prácticas y alcoholismo, situaciones que eran justificadas por los fanáticos y entrenadores, reproduciéndose actitudes propias de estrellas que se creen invulnerables. Además, muchos aprovechaban esta idolatría para actividades ilegales como la exportación de divisas en las giras al exterior, y la compra de bienes para vender en el mercado negro local, involucrándose en los bajos fondos soviéticos. Quienes también amparaban estos comportamientos, sobre todo cuando el atleta era especialmente talentoso, eran los burócratas del Estado que apadrinaban/sponsoreaban al equipo. De acuerdo con Edelman (1993), estos problemas estaban relacionados con la creciente influencia de estos "filántropos" (metsenaty) o patrones del juego ${ }^{22}$. Ellos eran jefes locales del Partido, responsables de una empresa, dirigentes sindicales o generales de la KGB o el ejército, y en la medida en que el carácter de entretenimiento del deporte de espectador se hizo evidente para las masas, la influencia de estos personajes creció. Estos solían despedir entrenadores, armar formaciones y tácticas, sobornar árbitros, arreglar partidos y "comprar" jugadores. Esta última era su especialidad, ya que su posición permitía el manejo de recursos como departamentos, autos, dinero y regalos para atraer a los jugadores, ante la inexistencia de un mercado formal. Esta actividad se volvió un gran y oscuro negocio, muchas veces encubierto por la prensa. Si bien el movimiento de jugadores, importante índice de profesionalismo, siempre fue común, en este período se generalizó, encontrando tibias regulaciones con pobres resultados. Para esto fueron importantes las facilidades de estos "filántropos" en el "acomodamiento" de los falsos amateurs en algún trabajo al que nunca asistirían. Ese status impedía que, cuando se producía una transferencia, el club que no contaba más con el jugador perciba dinero alguno. No existían contratos, ni propiedad: en este sentido los jugadores eran más libres que sus pares de occidente. Desde luego, los clubes más poderosos podían tentar jugadores con más

\footnotetext{
${ }^{22}$ Rol similar a los "padrinos" que señala Frydenberg (2011) para el caso argentino. Se trataba de agentes externos al club, figuras socialmente reconocidas (habitualmente políticos), que en algunas ocasiones utilizaban su ayuda como trampolín para obtener una fuerte posición en el seno de la institución.
} 
facilidad. Como señala Edelman, "Las estructuras formales eran suplementadas por un gran cantidad de prácticas informales" (1993, p.181). Este panorama no era patrimonio exclusivamente del mundo deportivo y se reproducía también en el ámbito de la producción, en donde surgieron grupos que operaban para quebrar la planificación económica (Broue, 1973).

\section{LA PERESTROIKA}

En paralelo, hacia fines de los setenta, tenían lugar una serie de profundos procesos sociales en los que muchos fenómenos culturales e identitarios occidentales, como los punks, skinheads y las hinchadas deportivas, tuvieron sus imitadores en el mundo juvenil soviético. Para Riordan (1988c), estos grupos expresaban una rebelión contra la jerarquía, directivas y autoridades imperantes en el mundo del ocio, demandando participación en los asuntos públicos. Se producía una desafección masiva de los organismos juveniles oficiales ${ }^{23}$ (Riordan, 1988a) que controlaban la mayoría de los espacios de ocio (artístico y deportivo), dando lugar a la creación de organismos y asociaciones juveniles informales, las cuales fueron reconocidas en 1986. Asimismo, muchas mujeres desafiaron las resolución oficiales que indicaban que deportes eran dañinos para ellas (Riordan, 1990), desarrollando estas actividades en claro desafío a estas disposiciones, siendo pioneras e inspiradoras de los primeros equipos de actividades como fútbol, judo y hockey.

Pero el hecho fundamental de la década del ochenta fue la perestroika o la "re-estructuración", iniciada en 1985. Presentada por Gorbachov (1987) como una reestructuración social, económica y democrática que rompería con el freno del crecimiento soviético, implicaba una serie de importantes cuestiones. Se introducía la contabilidad de $\operatorname{costos}^{24}$ (junto con aún más incentivos materiales para elevar la productividad), y las ganancias de empresas e individuos pasarían a estar determinadas por su efectividad, y no por la planificación estatal, estimulando así la producción y la competencia. Asimismo, el

\footnotetext{
${ }^{23}$ La Komsomol, juventud del Partido, había perdido seis millones de miembros en el último lustro (Riordan, 1990)

${ }^{24}$ Las empresas financiarían todos sus gastos por si mismas. Ellas serían las propias responsables de sus resultados. Sus pagos al presupuesto del Estado se redujeron.
} 
Estado reduciría sus compras fijas a las empresas, fomentaría la pequeña empresa, los contratos a granjas colectivas ${ }^{25}$, y el cierre de fábricas no rentables. La tónica general era individualista y anti-igualitarista. Se trata de una "desestatización" de una economía de gestión estatal centralizada, combinada con una serie de concesiones de tipo democrático. Pero la gestión de las empresas, que en el discurso oficial iba a estar en manos de los obreros, terminó siendo de la misma burocracia soviética monopolizadora del poder político, sobre todo una vez ocurrida la restauración capitalista. Se trató de una inyección de "orden jurídico" a su propia dominación, preparando un acuerdo con el gran capital y un desarrollo de mercado para convertirse en una nueva clase explotadora (Altamira, 1991). Fueron atacadas las conquistas sociales de la revolución de 1917 a través de una política de privatizaciones, que generarían desempleo y diferenciación social (Coggiola, 1991). Este es el contenido social de la Perestroika.

Estos cambios tuvieron como resultante una reducción en el apoyo estatal al deporte, lo que obligó al mundo deportivo a mantenerse por su cuenta y generar sus propios recursos: al igual que las empresas, los equipos debían autofinanciarse, lo cual implicaría revisar su retórica anticomercial. Sin embargo, no era el Estado la única fuente de ingresos de los clubes: existía una fuerte actividad voluntaria que tenía como objetivo conseguir dinero para financiar la actividad. Además, Edelman (1993) señala que las fábricas y sindicatos solían aportar el 15\% de los ingresos, que la venta de entradas, el alquiler de espacios para eventos sociales, casas de apuestas y la cuota de socio representaban otras fuentes de recursos. Otra fuente de recursos era la venta de periódicos y las giras de las estrellas por las provincias. Desde luego, esto era más frecuente en los deportes de equipo que en los individuales.

Pero en los últimos años de la URSS se aceleró la entrada de otros elementos propios del deporte occidental/capitalista. Surgió una prensa deportiva independiente, fuera del control del Estado y con menos compromiso con el sistema, por tanto libre de criticar a los $\operatorname{protagonistas}^{26}$. La "espartaquiada" siguió perdiendo terreno, ya que las

\footnotetext{
${ }^{25}$ En los que el pago depende la eficiencia de cada trabajador.

${ }^{26}$ Según Frydenberg (2011) la prensa juega un rol importante a la hora del desarrollo deportivo nacional. En el caso de la prensa soviética, estos cambios fueron importantes debido a que se habló con mayor libertad del falso amateurismo, los arreglos de partidos, favoritismo, drogas, doping, entre otras cuestiones.
} 
grandes figuras dejaron de participar (Riordan,1990). En las transmisiones de los eventos deportivos comenzaron a aparecer los comerciales: por ejemplo, los de la marca Coca-Cola en Seúl 1988. Asimismo, otras empresas extranjeras compraron espacios publicitarios en la televisión soviética, a cambio de la trasmisión del básquet y hockey estadounidenses. En sintonía con esto, muchos deportes comerciales como golf, fútbol americano y beisbol llegaron a la URSS (Riordan, 1990). En 1988 se creó el primer campo de golf soviético, utilizado para la diplomacia con gobiernos extranjeros y para entrenar a los nuevos golfistas soviéticos para la competencia internacional. Algunos millonarios extranjeros invirtieron en otros campos. La URSS se transformó en sede de torneos internacionales de motociclismo y Fórmula 1. También organizó exhibiciones entre equipos estadounidenses de futbol americano en tierra soviética, para promover la actividad. Billar, carreras de galgos y artes marciales tuvieron su lugar.

Hacia 1987, los equipos de fútbol soviéticos comenzaron a buscar sponsoreo de firmas extranjeras y a portar publicidad de compañías occidentales en sus indumentarias ${ }^{27}$. Los jugadores también esgrimieron a hacer sus reclamos por su participación en los comerciales: los futbolistas soviéticos habían realizado varias promociones para diversas compañías italianas en el mundial de $1990^{28}$ y reclamaban su parte. Ante la crisis económica los equipos hallaron una fuente de financiamiento en la venta de jugadores al exterior, lo cual estaba permitido inicialmente solo para aquellos mayores de 38 años, pero en la medida en que se hizo imprescindible, esta barrera fue removida. Las consecuencias fueron obvias: una caída en el nivel de la competencia local por la venta de los mejores talentos, lo que derivó en un descenso en la asistencia a los estadios. En simultáneo, a partir del permiso otorgado en 1987, aparecen una serie de emprendimientos cooperativos, vinculados a clubes deportivos, de salud, entre otras cuestiones (Riordan, 1990).

Toda esta situación llevó inevitablemente a pensar en una vuelta al profesionalismo parcial de entre-guerras. Esta idea dio pie a una disputa

\footnotetext{
${ }^{27}$ Vale aclarar que esto fue novedoso para la competencia doméstica. En las competencias continentales esto ya ocurria. Además, los contactos con empresas extranjeras fueron importantes a la hora de organizar y financiar los Juegos Olímpicos de Moscú 1980.

${ }^{28}$ Similar situación ocurriría con el tenista Andrei Chesnokov, quien ganaba mucho dinero en el circuito profesional, pero se le ponía un tope diario. En 1989, retuvo sus ganancias, rechazando entregar compensaciones a las autoridades soviéticas (Riordan, 1990)
} 
por el control de este proceso, en el que deportistas, entrenadores y directivos de clubes lucharon contra la burocracia estatal, episodio que se vio reflejado en la prensa, algo más liberada por las reformas $(\text { glasnost })^{29}$.

En 1988 una resolución gubernamental planteó la reestructuración del fútbol. En este proceso se enfrentaron dos campos claramente delimitados. En 1987, un grupo de deportistas creó una futbolnyi souiz, un tipo de asociación de fútbol con el propósito de proponer el profesionalismo y lograr una organización independiente de la actividad, asimilándose a la forma que adoptaba en occidente. Al año siguiente, el Goskomsport, órgano estatal a cargo del deporte, emitió un documento para reorganizar la actividad, en coordinación con la juventud del Partido, los sindicatos y los ministerios del interior y defensa. Este abogaba por un fuerte vínculo entre el Goskomsport y la nueva asociación, la cual sería catalogada como social-profesional, en lugar de independiente. Establecía una distinción entre los profesionales y aquellos que formalmente estaban en las fuerzas armadas, dado que los equipos autofinanciados co-existirían con aquellos financiados por los ministerios, esencialmente el Dinamo. Esta propuesta generó críticas. De acuerdo con Edelman, "Para que dichos planes se implementen con éxito, puede ser necesario crear otras reglas, procedimientos, leyes y prácticas culturales complementarias" (1990, p.47). Es decir, una de las cuestiones más acuciantes era la legal: ¿Qué posición tomarían la justicia soviética ante la emergencia de estos contratos y los conflictos que esto implicaría? Asimismo, algunos dirigentes clubísticos se preocupaban por la cuestión económica: no estaba especificado por cuanto tiempo el Goskomsport seguiría financiando a las instituciones, por lo que los clubes debían seguir buscando formas de autofinanciarse y generar ingresos. Los partidarios de la asociación deseaban hacerse cargo de las grandes ligas, copas y selecciones, abandonando su responsabilidad por la formación de juveniles y el acceso de las masas al deporte. Estos participantes directos en el deporte deseaban librarse de las ataduras de la burocracia y su interés estatal en el deporte, para poder desarrollar amplias políticas de financiamiento. Ellos abogaban por la creación de incentivos de rendimiento para asegurar los máximos esfuerzos. Criticaban a la burocracia, esgrimiendo sus propios conocimientos en el tema para sostener su posición: los burócratas estaban allí "de casualidad”. Desde el

\footnotetext{
${ }^{29}$ Transparencia informativa de los asuntos públicos promovida por la perestroika.
} 
lado estatal denunciaban que los deportistas solo querían crear una organización puramente comercial. Su propuesta era la de un pasaje hacia el autofinanciamiento de forma gradual. Cada quien protegía su interés. Finalmente, en junio de 1989 se declaró el profesionalismo ${ }^{30}$, eligiendo la "asociación de ligas de fútbol" (nombre en el que había mutado el proyecto inicial de futbolnyi souiz) un presidente favorable al autofinanciamiento no gradual. Pero el Goskomsport mantuvo un cierto control sobre la situación, e intentó trabajar a la par de la asociación. La situación lejos estuvo de perder su conflictividad. Desde el Estado, rápidamente se intentó acotar el rango de acción de la nueva asociación y comenzó una batalla por la representación del fútbol soviético ante los organismos internacionales. Por lo visto, el eje no era tanto el profesionalismo (que en realidad ya existía de forma encubierta), sino más bien la comercialización, es decir quien controlaría y lucraría cuando se dé la inevitable profesionalización.

El primer equipo en declararse profesional fue el Dnipro Dnipropetrovsk: realizó contratos por tres años, pagando bonus por rendimientos individuales. Los jugadores, ahora se veían obligados a rendir deportivamente, además de estar en una posición desventajosa "Hasta entonces, había sido relativamente fácil para un jugador insatisfecho abandonar su equipo y encontrar trabajo en otra parte la próxima temporada" (Edelman, 1993, p.229). En el pasado, no existían contratos que obligasen a los jugadores a vivir donde no quisiesen. Los movimientos de jugadores se justificaban de forma laxa.

El caso del futbolista Salenko, del Zenit, estableció en 1989 el primer pago de transferencia legal de la historia deportiva de la URSS. Se estableció una suma de 37.000 rublos, y el pago estándar se estableció en 25.000 rublos. Si el jugador era miembro de la selección nacional, esta cifra se duplicaba, y si era un juvenil se incrementaba un 50\%. El caso Salenko (Edelman,1993) da cuenta de la vigencia de las leyes capitalistas del deporte. Los equipos más débiles, con menos facilidades de

\footnotetext{
${ }^{30} \mathrm{Si}$ bien en este apartado se atiende especialmente al profesionalismo del deporte más popular, el fútbol, el mismo fenómeno descrito en estas líneas se desenvuelve en distintas actividades deportivas. Por ejemplo, 1988 es el año en que 14 ciclistas firman un contrato con la empresa de San Marino Alfa Lum, para crear el primer equipo profesional soviético de la disciplina. Asimismo, luchadores y boxeadores soviéticos ingresan a los rankings profesionales. La federación soviética de boxeo firma un contrato con los promotores estadounidenses que traslada 24 de sus boxeadores a dicha nación y otro con Japón, que se lleva 8 luchadores para la competencia local
} 
financiamiento, se vieron severamente perjudicados. En este contexto, los entrenadores manifestaron preocupación por la disciplina y la seriedad en el trabajo de los futbolistas, ante la situación de un contrato.

En el plano olímpico, ya no se ocultó más el incentivo que se proporcionaba en rublos a los destacados atletas, especialmente en la medida en que el movimiento olímpico mundial gradualmente aceptó profesionales.

Queda de manifiesto en este apartado que el profesionalismo empalma a la perfección con una lógica de gestión propia de los tiempos de la perestroika. Aun así, el abandono del amateurismo lejos estuvo de terminar de clarificar y estabilizar la situación de los deportistas, quienes ya eran reconocidos por su actividad al finalizar la perestroika en diciembre de 1991.

\section{ConClusiones}

El desarrollo ilustrado en este texto no debe hacernos caer en una mirada dicotómica, entre el "deporte obrero" y el burgués. Como agudamente señala Sparks (2009), el inspirador (sobre todo en los primeros años) del movimiento deportivo soviético, Pyotor Lesgaft (1837-1909), reflejó los ideales de la burguesía liberal de fines del siglo XIX: autodisciplina, conciencia social a través de la educación física, emancipación social de la mujer mediante la liberación de su cuerpo, la camaradería y el objetivo de un desarrollo armónico individual, muchos de ellos puntos en común con el olimpismo burgués. Estos objetivos no podían dejar de reflejar el atraso relativo de la sociedad soviética, su naturaleza altamente contradictoria $\mathrm{y}$ su desarrollo desigual y combinado $^{31}$. Como en muchas de las esferas de la vida social, el escaso desarrollo de una burguesía local, que en el caso tradicional era la clase ociosa que desarrollaría el deporte, fue reemplazado por el rol del Partido, quien controló el asociativismo que se desarrolló posteriormente. Se pueden entender así los puntos en común entre el movimiento olímpico y el "deporte obrero", incluso de los primeros años de la revolución. En principio, los líderes soviéticos deportivos no eran contrarios al amateurismo en sí mismo. Más bien se oponían a sus

\footnotetext{
31 Según Lenin (1973) la formación social y económica sociedad soviética posrevolucionaria estaba integrada por: economía natural, pequeña producción mercantil, capitalismo privado, capitalismo de Estado y socialismo
} 
vínculos con el elitismo de la clase dominante, quien deseaba conservar para sí este espacio de ocio, descalificando a los trabajadores y prohibiendo su participación. Entonces, de acuerdo con Riordan (2006), los soviéticos creían ser los verdaderos defensores del amateurismo, organizando olimpiadas y competencias para el disfrute de hombres y mujeres de la clase trabajadora, sin importar su procedencia.

Desde luego, estos puntos en común se volvieron más pronunciados, en la medida en que la URSS fue ingresando gradualmente al movimiento olímpico y adoptando características propias del deporte moderno.

La discusión del amateurismo-profesionalismo tiene una larga trayectoria. Como fue dicho, el amateurismo fue esgrimido inicialmente para ser un bloqueo para el ingreso al deporte de los trabajadores, por parte de la burguesía. Esto especialmente a partir de la tendencia a la profesionalización de los deportistas, para quienes podría ser una vía de ascenso social. Un cuadro total que representaba una amenaza para el dominio y control por parte de los "caballeros" amateurs. Eventualmente, la propia naturaleza del fenómeno, enmarcado en la sociedad capitalista, comenzaría a erosionar esto.

Al analizar el caso soviético se observa que, una vez saldada la disputa en torno al vínculo del deporte soviético con el burgués, este se volvió menos orientado a las masas y a la perspectiva de transformarlas; lejano a la idea inicial de una suerte de contra-poder deportivo en los términos de García del Valle (2016), en un contexto de abandono de posiciones más radicalizadas en distintos ámbitos (Ibarrola, 2018). Al contrario, se orientó al desarrollo de atletas de alto nivel, para lo cual no fue necesario promover la participación de millones de trabajadores: las autoridades soviéticas habían terminado por aceptar competir bajo las condiciones del mercado internacional, con la consiguiente aparición de una burocracia profesionalizada en la administración deportiva (Sparks, 2009).

Es indudable que los soviéticos suscribieron al modelo de deporte moderno, el cual posee características propias de la sociedad burguesa (su contexto de emergencia) y reproduce sus valores (Brohm,1993): secularismo, igualdad de oportunidades, especialización, racionalización, organización burocrática, cuantificación y búsqueda del récord (Guttman, 2007), junto con la comercialización, la competición, la superación al contrario, la universalidad, el profesionalismo (entendido como el ascenso social hacia una elite), el éxito individual y la ganancia (García 
del Valle, 2016). En este punto disiento con García del Valle (2006), quien señala que los rasgos en común entre el "deporte obrero" y el burgués-moderno, se deben al carácter industrial de ambas sociedades soviética y occidental. Lejos están de verse reflejados aspectos tales como el récord o la racionalización en los primeros tiempos del "deporte obrero". Más bien, estos puntos en común obedecen al desarrollo particular de la sociedad soviética y a las decisiones políticas de sus dirigentes.

En estas páginas se visibiliza un proceso gradual, pero sostenido de transformación del deporte, que culmina con la abolición del amateurismo formal y el comienzo del profesionalismo. Se trata de fenómenos indisociables de la perestroika, entendida como un corolario de un largo proceso hacia la vuelta al capitalismo.

Las reformas emprendidas abrieron la posibilidad de que una variedad de empresarios y grupos no vinculados al gobierno puedan generar sus propios entretenimientos y prácticas de ocio. Agentes privados organizaron shows de lucha, boxeo y beach-voley, entre otros. Asimismo, los problemas financieros propios de la apertura económica repercutieron en los clubes. ¿Cuánto afectaría la crisis económica de los noventa a la asistencia a los estadios? ¿Hasta qué punto el deseo de consumo del público soviético era tal como para solventar un profesionalismo? ¿Se desarrollaría lo suficientemente rápido un mercado deportivo? En este contexto, no es de extrañar que la respuesta ante las dificultades económicas derivara en un aumento del costo de las entradas.

Si lo planteado en un trabajo anterior (Ibarrola, 2018) nos hablaba de una tendencia universal del deporte mundial (moderno), que tenía su efecto particular en las primeras décadas de la URSS, lo trabajado en el presente escrito refuerza lo dicho allí: se siguió desenvolviendo un proceso de características similares a las que tuvo en occidente, pero bajo la sombra de la hipocresía estatal. Este solo atinó a terminar con la farsa cuando el principal motivo de la misma se extinguió: la aceptación gradual de la entrada de profesionales a los deportes del mundo. La existencia de un movimiento de deportistas, consciente de la irregularidad y la falsedad histórica de su situación, que vio en la perestroika una posibilidad de formalizar su situación, es una prueba de ello. También lo es que, durante décadas, presionado por la adhesión e ingresos a la dinámica del deporte moderno, aparecieron fenómenos propios del "deporte burgués" comercial, como los "filántropos". 
Las condiciones excepcionales de la revolución rusa dieron lugar a una sociedad de tipo transicional con destino abierto, cuyo porvenir estaba condicionado a la suerte de la revolución mundial. Esta premisa concluye el trabajo anterior (Ibarrola, 2018). Los acontecimientos que abarcan el presente escrito se contextualizan en la definitiva consolidación de una burocracia restauracionista que, como plantea Trotsky, aborta y boicotea los sucesivos intentos revolucionarios en el mundo. En este sentido, el proceso deportivo descripto aquí expresa el camino hacia la restauración del capitalismo, transformando definitivamente a los deportistas en mercancías.

\section{BIBLIOGRAFÍA}

Altamira, J. (1991). La perestroika y América Latina. En Defensa del Marxismo, 2, 5-11.

Brohm, J. (1993). 20 tesis sobre el deporte. En J. Barbero (Ed.), Materiales de sociología del deporte (pp. 47-55). Madrid: La Piqueta.

Broue, P, (1973). El partido bolchevique. Madrid: Editorial Ayuso.

Coggiola, O. (1991). La burocracia stalinista y Trotsky. En Defensa del Marxismo, 1, 16-21.

Edelman, R. (1990). The Professionalization of Soviet Sport: The Case of the Soccer Union. Journal of Sport History, 1, 44-55.

Edelman, R, (1993). A History of Spectator Sports in the USSR. Nueva York: Oxford University Press.

Frydenberg, J. (2011). Historia social del fútbol: del amateurismo a la profesionalización. Buenos Aires: Siglo veintiuno editores.

García del Valle, M. (2006). Deporte y Socialismo, ¿un modelo socioeconómico para otro modelo deportivo?. Universidad del País Vasco, Tesis de Grado no publicada. Obtenida el 21 de junjio de 2020 en: https://addi.ehu.es/bitstream/handle/10810/19977/TFG MIKEL\%20TAPI A.pdf? sequence $=1 \&$ isAllowed $=\mathrm{y}$

García Ferrando, M. (1990). Aspectos sociales del deporte. Una reflexión sociológica. Madrid: Alianza Editorial. 
Gounot, A. (2007). De los ideales de salud a la ambición por los récords. Características y evolución de la ideología deportiva de la Unión Soviética en el periodo de entreguerras. Materiales Para La Historia Del Deporte, 5, 9-24.

Gorbachov, M. (1987). Perestroika. Nuevas ideas para nuestro país y el mundo. Buenos Aires: Emecé.

Guttman, A. (2007). Sport: The first five millennia. Massachusetts :University of Massachusetts Press.

Ibarrola, D. (2018). Reflexiones acerca del deporte soviético: de la revolución a la adaptación a occidente. Revista Lúdicamente, 14.

Lenin, V. (1973). Obras, tomo XII (1921-1923). Moscú: Progreso.

Riordan, J. (1977). The Father of Russian Physical Education. Journal of Physical Education and Recreation, 2, 66-71.

Riordan, J. (1988). The Role of Sport in Soviet Foreign Policy. International Journal, 4, 569-595.

Riordan, J. (1988). The USSR and olympic boycotts. The International Journal of the History of Sport, 3, 349-359.

Riordan, J. (1988). Soviet Youth: Pioneers of Change. Soviet Studies, 4, 556572.

Riordan, J. (1990). Playing to New Rules: Soviet Sport and Perestroika. Soviet Studies, 1, 133-145.

Riordan,J. (1994). The Strange Story of Nikolai Starostin, Football and Lavrentii Beria. Europe-Asia Studies, 4, 681- 690

Riordan, J. (2006). Amateurism, Sport and the Left: Amateurism for All Versus Amateur Elitism. Sport in History, 3, 468-483

Riordan, J. (2007). The Impact of Communism on Sport. Historical Social Research ,1, 110-115 
Rodríguez Quijada, M. y Molkova, S. (2018). URSS vs. EEUU, RDA vs. RFA: Guerra Fría en los Juegos Olímpicos de Verano (1952-1988). Retos, 33, 37-39.

Sparks, J. (2009). Red sport, Red tape: The Olympic Games, The soviet sports bureaucracy, and the Cold War, 1952-1980. University of North Carolina, Tesis doctoral no publicada. Obtenida el 21 de junio de 2020 en: https://cdr.lib.unc.edu/concern/dissertations/0r9674344.

Truan, J. (2008). El movimiento gimnástico del Este (2. parte). Apunts, Educación Física y Deportes, 93, 12-18. 